RAD Conference Proceedings, vol. 3, pp. 207-212, 2018

ISSN 2466-4626 (online) | DOI: 10.21175/RadProc.2018.44

www.rad-proceedings.org

\title{
INADEQUATE USE OF HERBAL DIETARY SUPPLEMENTS AMONG PATIENTS UNDER CHRONIC TREATMENT
}

\author{
Maja Cvetković ${ }^{*}$, Dušan Ilić1 ${ }^{\text {, Dušica Stojanovićć,2 }}$ \\ ${ }^{1}$ Department of Pharmacy, Faculty of Medicine, University of Niš, Niš, Serbia \\ ${ }^{2}$ Institute for Public Health, Niš, Serbia
}

\begin{abstract}
The use of herbal supplements and medicines is increasing rapidly as most people consider them to be of natural origin and therefore safe. Many herbal medications are used to treat diseases but while they are often efficacious, their safety has not sufficiently been considered by physicians or users. One particular safety concern is the risk of interactions with drugs, which often leads to toxicity or loss of therapeutic efficacy. A significant number of patients combine herbal remedies with prescription medications and there is growing evidence for interactions of drugs with herbal remedies or single compound originating from plants. The aim of this paper is to evaluate the possible interactions between chronic patient therapy and herbal substances. The research is presented as a descriptive study which included patients of 30 to 80 years of age, who were randomly selected in Niš from September to December 2017 and agreed to be interviewed as well as completed the questionnaires. We surveyed 157 patients, 115 respondents (73.24\%) reported use of dietary supplements. In total, 105 (66.87\%) interactions with potential clinical significance were identified. The 5 most common natural products with a potential for interaction (garlic, valerian, ginkgo, and St John's wort) accounted for $68 \%$ of the potential clinically significant interactions. The 4 most common classes of prescription medications with a potential for interaction (antithrombotic medications, sedatives, antidepressant agents, and antidiabetic agents) accounted for $94 \%$ of the potential clinically significant interactions. No patient was harmed seriously from any interaction. It is an imperative that pharmacists and doctors ask patients what they are using within their chronic illness treatment and estimate the possible use of a dietary supplement based on the data obtained.
\end{abstract}

Key words: Food, herbal dietary supplements, nutrition, drug interactions

\section{INTRODUCTION}

Food can alter the absorption, distribution, metabolism, and elimination of a drug via physiological and physical-chemical mechanisms. The clinical significance of drug-drug and food-drug interactions is focused on and limited to changes in drug metabolism inside liver cells and the proximal part of the small intestine, where the largest amount of drugmetabolizing enzymes and transporters are situated .[1]. The significance of pharmacokinetic and pharmacodynamic drug-drug or drug-food interactions is brought into question when there is an increased toxicity and/or a lack of therapeutic effects with standard clinical drug dosage regimens.[2]. Although some of the interactions can be used to improve the dosage regimen or clinical outcomes, most of them will have unforeseen and, sometimes, life-threatening consequences.

Age, malnutrition, malabsorption, liver disease, renal insufficiency, chronic therapy administration, and pharmacogenetics are known risk factors for the occurrence of drug-drug and drug-food interactions. [3]. There are three main categories of drug-drug interactions: pharmacodynamic, pharmaceutical, and pharmacokinetic. [4]. The knowledge of mechanisms through which the drugs are metabolized can aid in the understanding of many pharmacokinetic interactions, thereby increasing the ability to anticipate and prevent potentially dangerous interactions. Changes in the systemic availability and oral bioavailability of drugs may be associated with metabolism induction, rapid elimination and subdosing or vice versa, overdosing, or toxicity. [5,6]. In the case of a pharmacokinetic interaction, the two most important mechanisms are drug metabolism via CYP450 enzymes and the impact of the P-glycoprotein on the bioavailability of the drug. $[7,8]$. In humans, the CYP450 enzyme oxidase system has more than 40 enzyme subtypes, while 6 of them are responsible for $90 \%$ of drug oxidation in humans: $1 \mathrm{~A} 2$, 3A4, 2C9, 2C19, 2D6, and 2E1. The expression of CYP450 is different for each person, which explains the differences in the bioavailability of certain drugs. About $30 \%$ of the $\mathrm{CYP}_{3} \mathrm{~A}_{4}$ isoenzyme is located in the liver, with the majority of the enzyme activity (about 70\%) expressed in the intestinal wall, while the rest of the activity is registered in the testicles, lungs, kidneys, and the central nervous system. It is known that this isoenzyme metabolizes over 100 drugs; therefore, the

*maja.celebrity@gmail.com 
M. Cvetković et al., Inadequate use of herbal dietary supplements..., RAD Conf. Proc., vol. 3, 2018, 207-212

inhibition of the activity of $\mathrm{CYP}_{3} \mathrm{~A}_{4}$ causes an elevation of serum concentration of the drug metabolized by this enzyme. [9].

The world is increasingly acknowledging the importance of healthy food and dietary supplements in order to compensate for the lack of micro- and macronutrients, which would result in the improvement of health.[10]. Accordingly, an increasing number of patients use OTC ("Over The Counter") products of their own accord along with their prescribed therapy, thereby increasing the risk of potentially dangerous interactions. Certain foods, herbal medicines and OTC products can regulate the in vivo and in vitro activity of certain enzymes responsible for drug metabolism, and the influx and efflux of transporters expressed on the enterocyte membrane, and may play a major role in the most relevant clinical drug-food interactions. Supplements can possibly change the bioavailability of the drug after oral administration, which can lead to a change in concentration, affecting the efficacy or toxicity of the drug. [11]. Food delays gastric emptying, raises the $\mathrm{pH}$ of the proximal part of the small intestine, increases blood flow through the liver, and increases the time of the gastrointestinal transit, as compared to fasting. $[11,12]$.

In recent years, an increasing number of people in our country have started using OTC products. For most people, these products are their first choice in the selfmedication of minor health issues. The majority of the population considers OTC products to be of natural origin and safer as compared to drugs. Having in mind the increasing use of ancillary medications and herbal drugs, their usage and combination with chronic treatment have become an important issue for public health. The aim of this paper is to evaluate the possible interactions between chronic patient therapy and herbal substances.

\section{MATERIALS AND METHODS}

The research is presented as a descriptive study which included patients of 30 to 80 years of age, who were randomly selected in the DONA FARM pharmacy in Niš from September to December 2016 and agreed to be interviewed. The survey was conducted using an anonymous questionnaire containing 13 open-ended and closed-ended questions. The questionnaire consisted of several parts: the sociodemographic characteristics of the consumer (age, gender, education level), the chronic treatment of the patient, the use of a herbal supplement, the source of recommendations on how to use them, and their adverse effects. All the questions in the survey offered answers, except for the question about dietary supplements, within which it was necessary to enter the OTC product that the patient was using.

Respondents completed survey independently in the presence of a pharmacist, who was available in case of difficulties in understanding certain concepts. The respondents were informed about the objectives of the research, and the percentage that declined to participate in the study was 20\%. 157 correctly completed questionnaires were selected and they were the subject of the further analysis. Criteria for the exclusion from the study were persons younger than 30, pregnant women, and cancer patients. The study was conducted in accordance with the Declaration of Helsinki. [13].

A statistical analysis of the results was performed using descriptive and analytical statistics in Excel 2010 on the Windows 7 operating system.

\section{RESULTS}

Of the total respondents, 67 (42.67\%) were female, while $90(57.32 \%)$ were male. Dietary supplements were used by 115 respondents (73.24\%). Most patients, as many as 105 (66.87\%), used some sort of dietary supplement in addition to their regular therapy. Of the total number of respondents who used dietary supplements, the largest number, 42 (36.52\%), used multivitamin products, and 26 respondents (22.6\%) used Ginkgo biloba in combination with chronic treatment. A somewhat smaller number, 15 (13.04\%) of them, used products based on St John's wort, while 11 of them (9.57\%) consumed ginseng. Other supplements, which are not interesting for this research, were used by 21 respondents (18.26\%). The demographic characteristics of the population are summarized in Table 1.

Table 1. The demographic characteristics of the population

\begin{tabular}{|c|c|c|c|c|c|c|}
\hline \multirow{4}{*}{ A } & \multirow{2}{*}{ GENDER } & \multicolumn{4}{|c|}{ AGE (YEARS) } & \multirow{2}{*}{ TOTAL } \\
\hline & & $30-40$ & $41-50$ & $51-60$ & $>61$ & \\
\hline & MALE & 6 & 9 & 26 & 49 & 90 \\
\hline & FEMALE & 5 & 9 & 21 & 32 & 67 \\
\hline \multirow{6}{*}{ B } & \multirow{2}{*}{ EDUCATION } & \multicolumn{4}{|c|}{ AGE (YEARS) } & \multirow{2}{*}{ TOTAL } \\
\hline & & $30-40$ & $41-50$ & $51-60$ & $>61$ & \\
\hline & ELEMENTARY & 1 & o & 4 & 8 & 13 \\
\hline & SECONDARY & 2 & 6 & 18 & 31 & 57 \\
\hline & POST-SECONDARY & 4 & 7 & 9 & 16 & 36 \\
\hline & TERTIARY & 4 & 5 & 16 & 26 & 51 \\
\hline
\end{tabular}


Part A clearly shows that more consumers were male, with the dominant age group being respondents over 61 years of age-49 (54.44\%). As for the female respondents, their number was slightly smaller than that of men, although the age structure was similarthere were 32 respondents $(47.76 \%)$ older than 61 . In Part B, the surveyed patients were categorized by education. The largest number of respondents, 57 $(36.3 \%)$, were at the level of secondary education.
When asked about the source of the recommendations for dietary supplements, the majority of the respondents, 53 (46.49\%) of them, answered that advice was given by a pharmacist; a slightly smaller number, 33 (28.66\%), received the recommendation from a doctor, while a considerable percentage of respondents received supplement usage advice from the media-16 (14.01\%)-and from a friend-13 (10.82\%) (Figure 1).

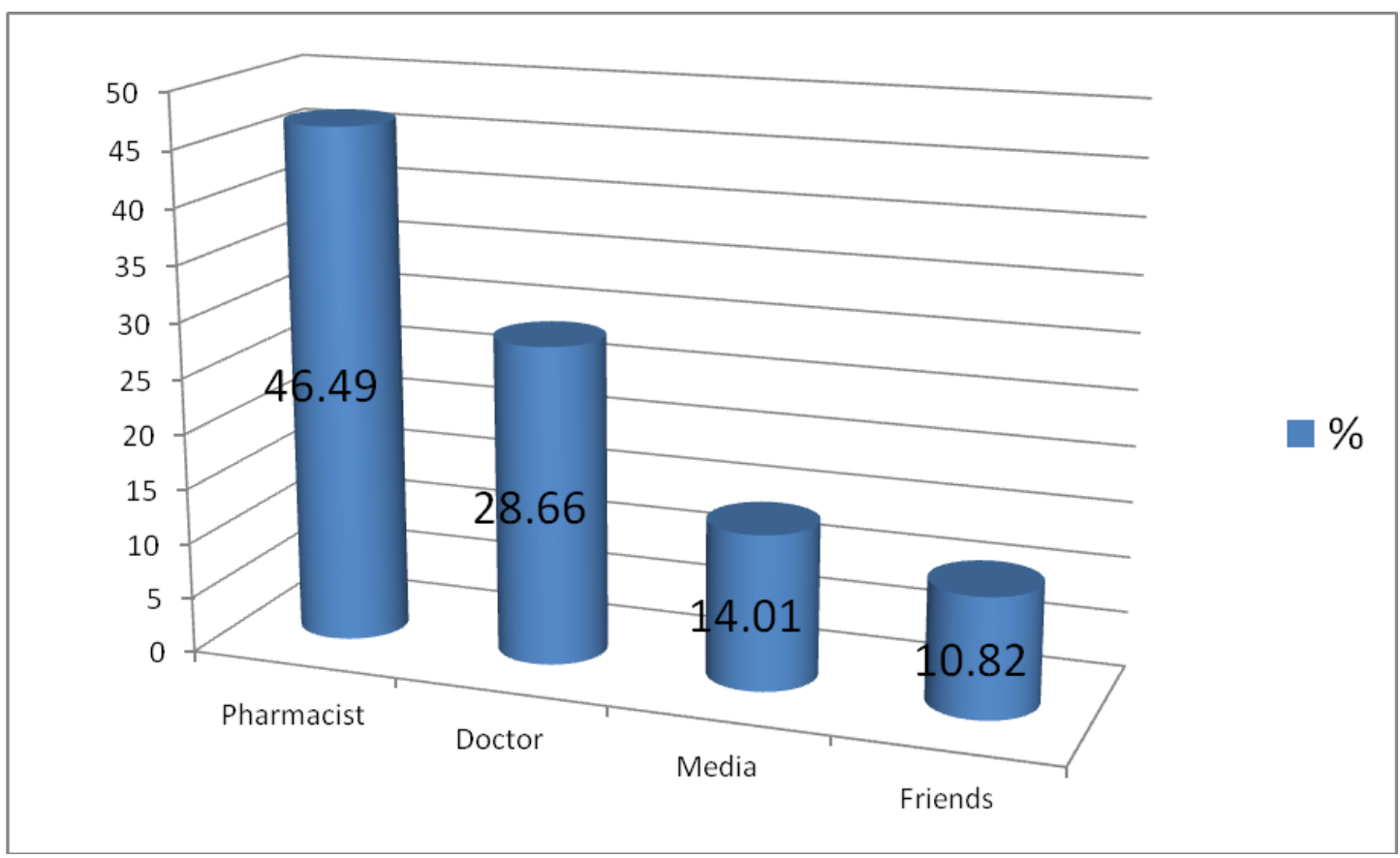

Figure 1. Source of dietary supplement recommendations (\%)

Figure 2 shows that the majority of subjects, 77 (66.88\%), purchased herbal supplements at a pharmacy. A smaller portion of the population, 24 (21.02\%) of them, purchased the supplements in health food stores, 12 of them (10.83\%) acquired them over the Internet through online shopping, while only two patients $(1.27 \%)$ purchased supplements in the supermarket. Most of the respondents who participated in the survey were older patients who had been receiving chronic treatment. The vast majority of patients consumed dietary supplements in addition to chronic therapy. When asked if they were aware of the possible interactions between their chronic treatment and a dietary supplement, most of them, 41 (39.05\%), gave a negative answer. A smaller number of respondents, 31 (29.52\%) responded that a pharmacist informed them about the possible interactions, 20 of them (19.05\%) responded that both a doctor and a pharmacist informed them about the possible interactions, while only $13 \quad(12.38 \%)$ received information about the interactions from a doctor in a primary health care institution. In our study, $11.11 \%$ of the total number of patients who consumed Ginkgo biloba were taking it in combination with one of the vitamin $\mathrm{K}$ antagonists, most often warfarin. All patients had their therapy prescribed by a physician, and they answered negatively when asked whether they were familiar with the possible interactions between the drugs that were used as part of their chronic treatment and the supplements. In our study, a huge number of patients (96.29\%) who consumed Ginko biloba products simultaneously took one of the following analgesics: ibuprofen (46.35\%), diclofenac (31.53\%), paracetamol (13.02\%), or matamizole-sodium (9.1\%). As many as $55.55 \%$ gave a negative answer to the question whether they were aware of the possible interactions of analgesics and supplements, 25.94\% of them were warned by pharmacists about the potential interactions, while only $18.51 \%$ of the respondents were informed by the doctor about the potential harmful interactions. As for the chronic administration of acetylsalicylic acid, most of the patients (33.33\%) simultaneously consumed some Ginkgo biloba products, although most of them had been warned of dangerous interactions, both by the physicians and the pharmacists. None of the respondents used St. John's wort preparations in combination with oral contraceptives, while $20 \%$ of them were taking antidepressants simultaneously with St. John's wort, where patients gave a negative answer to the question whether they were aware of possible interactions. The most commonly observed interactions of St. John's 
wort are those with oral contraceptives, which reduces their performance, and with antidepressants, which increases the risk for the occurrence of the serotoninergic syndrome. In our study, $9.57 \%$ of the respondents used ginseng. Of the total number of those who used ginseng, $27.27 \%$ used a combination of ginseng and warfarin and none of them had been informed of the possible interactions between the drug and the supplement.

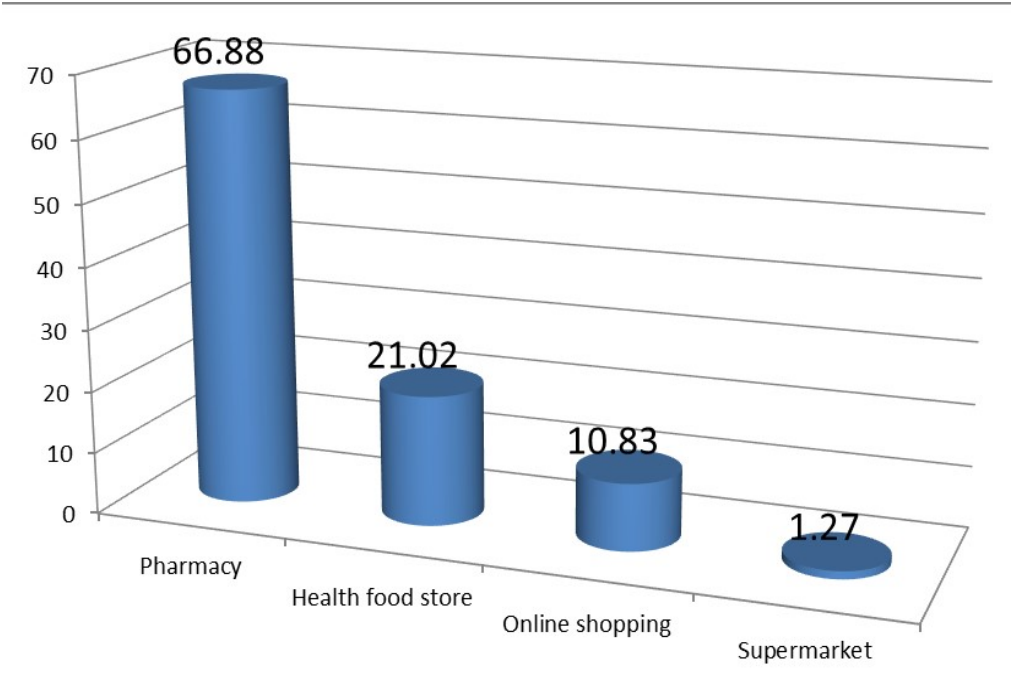

Figure 2. Place of dietary supplement purchase (\%)

\section{DisCUSSION}

Herbal dietary supplements are increasingly used in the population and are available both in pharmacies and in supermarkets and health food stores. [14,15]. Dietary supplementation can be a good choice and there is a lot of discussion about this issue in pharmaceutical and medical professional public .[16]. If used properly, these products can help the treatment of various diseases, while their irrational use and combination with chronic therapy can cause serious side effects. Modern researches emphasize the importance of the association between pharmacology and nutrition integration with the aim of making the therapy of these diseases more efficient; further investigations in the field of nutrigenomics will give more detailed recognition of possible ways to efficiently use nutrition with the aim of prevention. [17]. People often think that everything natural is safe, but it is not always so. Many plants are not suitable for different medical conditions, some are toxic in high doses, and some of the interactions between a herbal drug and chronic treatment can be fatal. Recently, the World Health Organization has estimated that $80 \%$ of the population relies on herbal products for the purpose of maintaining and enhancing their health. In Germany, approximately 600-700 herbal medicines are available and prescribed by their doctors. In the past 20 years, the United States population has witnessed an increased tendency of using herbal preparations. [18].

Many herbal dietary supplements are safe to use; however, there is a list of plants that can interact with drugs, not only due to changes in the absorption and metabolism of the active substances themselves, but also due to the modulation of the CYP450 enzyme system. [19]. Most drugs are metabolized by the $\mathrm{CYP}_{3} \mathrm{~A} 4$ isoenzyme, which is an intestinal barrier for the absorption of drugs and xenobiotics, which in turn allows optimum control of the plasma concentration of the drug. Using citrus juices, teas, tinctures based on St. John's wort, and dietary supplements may be the source of many life-threatening clinical interactions people are not aware of. [20-21]. The most commonly used herbal supplements in our study were based on Ginkgo biloba (22.6\%). This would not be so terrible if most patients were not receiving chronic treatment and taking a greater number of drugs simultaneously.

Ginko biloba is a plant rich in flavonoids (ginkgolide, quercetin, kaempferol, coumaric acid), biflavonoids, and proanthocyanidins. It is recommended in the treatment of Alzheimer's disease, Meniere disease, vertigo, intermittent claudication, peripheral arterial disease, and is mainly used by elderly patients who simultaneously take many drugs within their chronic therapy. [14]. Recent studies have shown that Ginko biloba interacts with vitamin $\mathrm{K}$ antagonists via CYP2C9, thereby increasing the risk of bleeding [10]. Non-steroidal anti-inflammatory drugs (NSAIDs), particularly aspirin, easily interact with herbal products which have an anti-aggregation potential for platelets, thereby increasing the risk of bleeding. High doses of Ginkgo biloba extract (10$100 \mathrm{mg} / \mathrm{kg}$ per day) can inhibit platelet aggregation and increase the risk of bleeding when consumed with aspirin and NSAIDs. [14, 15, 22]. St. John's wort (Hypericum perforatum) is traditionally used to treat insomnia and depression. [15, 23]. The crude extract of St. John's wort is a complex mixture of several active compounds: hypericin, quercetin, isoquercetin, hyperforin, and several bioflavonoids. Hyperforin is the 
main compound responsible for the antidepressant activity of St. John's wort, inhibiting the reuptake of serotonin, dopamine, and noradrenaline. Many preclinical and clinical trials have shown that hyperforin is also a strong inducer of CYP1A2, CYP2C9, CYP2C19, CYP3A4, and CYP2E1 enzymes and Pglycoproteins in the liver and small intestine. [15,23]. In all cases, the interaction was a consequence of the induction of the metabolism and rapid elimination of the drug taken at the same time or a few days after the consumption of St. John's wort preparation, with a high risk of therapy failure. $[15,23,24]$. Numerous clinical studies have showed that St John's wort decreases plasma concentrations of the following drugs: amitriptyline, indinavir, methadone, midazolam, simvastatin, tacrolimus, theophylline, and warfarin.[18]. Intermenstrual bleeding and unplanned pregnancy are also the result of simultaneous therapy with oral contraceptives and St. John's wort dietary supplements. There is evidence that St. John's wort increases skin sensitivity to ultraviolet rays and increases the risk of allergic reactions. [18].

Ginseng is a plant whose use is widespread. Typically, two types of ginseng are used: Chinese (Panax ginseng) and Siberian (Eleutheroccus senticosus). They are used to relieve many symptoms, such as fatigue, weakness, loss of concentration, impotence, and anxiety. Even though Siberian ginseng has showed no effect on the plasma concentration of many drugs, Chinese ginseng produces harmful effects when combined with warfarin. [25].

Most patients (36.52\%) used multivitamin preparations in addition to their regular therapy. The supplements used are rich in B-group vitamins, magnesium, and zinc. Latest research has pointed at a growing number of interactions between B-group vitamins and certain drugs. One study showed that the concomitant use of vitamin $\mathrm{K}$ antagonists and vitamins B6 and B9 can inhibit the effect of the drug. [26]. In our study, no patients simultaneously used a combination of vitamin $\mathrm{B}$ and a vitamin $\mathrm{K}$ antagonist. In addition to the vitamin $\mathrm{B}$ complex, the same study indicated that vitamin $\mathrm{E}$ combined with vitamin $\mathrm{K}$ antagonists could reduce the absorption of the drug. Our survey had no patients who used the mentioned combination. The greatest risk of adverse interactions was exhibited by patients who were on anticoagulant therapy. [27]. Having reviewed the literature, we acquired information about potential interactions that occur between ibuprofen and vitamin $\mathrm{E}$ or niacin (B3), which may cause increased bleeding. [28]. An increased risk of bleeding can occur as a result of simultaneous administration of aspirin with vitamin $\mathrm{E}$ and niacin (B3), while the coadministration of aspirin and vitamin $\mathrm{C}$ potentiates the negative effects of aspirin. [28].

In addition to aspirin and ibuprofen, naproxen may enter into interaction with vitamin $\mathrm{E}$ and niacin, which causes increased bleeding. [28] Literature also contains information on a decreased absorption of beta-blockers because of the co-administration of vitamin C. [18, 29].

\section{CONCLUSION}

In our country, an increasing number of people resorts to self-medication, while not being familiar with the positive sides, risks, and side effects of dietary supplements and herbal preparations, as well as their possible interactions with drugs.

Future efforts should focus on raising awareness and the dissemination of knowledge among patients regarding potentially undesirable interactions between the drug and dietary supplements. It is the duty of health workers to provide patients with comprehensive advice and information about the use of drugs and dietary supplements, as well as the possible risks and interactions due to their simultaneous use. It is an imperative that pharmacists and doctors ask patients what they are using within their chronic illness treatment and estimate the possible use of a dietary supplement based on the data obtained.

\section{REFERENCES}

1. G. K. Dresser, D. G. Bailey, "A basic conceptual and practical overview of interactions with highly prescribed drugs," Can. J. Clin. Pharmacol., vol. 9, no. 4, pp. 191 - 198, Feb. 2002. PMid: 12584577

2. J. H. Lin, A. Y. Lu, "Inhibition and induction of cytochrome P450 and the clinical implications," Clin. Pharmacokinet., vol. 35, no. 5, pp. 361 - 390, Nov. 1998.

DOI: 10.2165/00003088-199835050-00003 PMid: 9839089

3. R. M. Goldberg, J. Mabee, L. Chan, S. Wong, "Drugdrug and drug-disease interactions in the ED: analysis of a high-risk population," Am. J. Emerg., vol. 14, no. 5, pp. $447-450$, Sep. 1996.

DOI: 10.1016/So735-6757(96)90147-3 PMid: 8765105

4. M. Shou, "Prediction of pharmacokinetics and drugdrug interactions from in vitro metabolism data," Curr. Opin. Drug Discov. Dev. Vol. 8, no.1, pp. 66 - 77, Jan. 2005. PMid: 15679174

5. P. B. Watkins, "Drug metabolism by cytochromes $\mathrm{P} 450$ in liver and small bowel," Gastrointest. Pharmacol. vol. 21, no. 3, pp. $511-525$, Sep.1992 PMid: 1516957

6. M. F. Paine et al., "The human intestinal cytochrome P450 pie," Drug Metabol. Dispos. vol. 34, no. 5, pp. 880 - 886, May 2006.

DOI:10.1124/dmd.105.008672 PMid: 16467132

7. D. Shaw, G. Ladds, P. Duez, E. Williamson, K. Chan, "Pharmacovigilance of herbal medicine," J. Ethnopharmacol., vol. 140, no. 3, pp. $513-518$, Apr. 2012.

DOI: 10.1016/j.jep.2012.01.051

PMid: 22342381

8. H Schilcher, S Kammerer, $\mathrm{T}$ Wegener, "Pflanzenprofile," in Leitfaden Phytoterapie, München, Deutschland: Elsevier GmbH, Urban \& Fisher Verlag, 2007, kap. 2. (H Schilcher, S Kammerer, T Wegener, "Plant profiles," in Phytotherapy Guide, Munich, Germany: Elsevier GmbH, Urban \& Fisher Verlag, 2007, ch. 2.)

9. Z. Bojanic, N. Bojanic, V. Bojanic, "Drug interactions with grapefruit," Med Pregl. vol. 63, no. 11 - 12, pp. $805-810$. Nov-Dec. 2010

PMid: 21553459 
M. Cvetković et al., Inadequate use of herbal dietary supplements..., RAD Conf. Proc., vol. 3, 2018, 207-212

10. A. De Boer, F. van Hunsel, A. Bast, "Adverse food-drug interactions,” Regul. Toxicol. Pharmacol., vol. 73, no. 3, pp. $859-865$, Dec. 2015 .

DOI: $10.1016 /$ j.yrtph.2015.10.009

PMid: 26482404

11. D. Genser, "Food and drug interaction: consequences for the nutrition/health status," Ann. Nutr. Metab., vol. 52, suppl. 1, pp. 29 - 32, Mar. 2008.

DOI: $10.1159 / 000115345$

PMid: 18382075

12. B. N. Singh, B. K. Malhotra, "Effects of food on the clinical pharmacokinetics of anticancer agents," Clin. Pharmacokinet., vol. 43, no. 15, pp. 1127-1156, 2004. DOI: 10.2165/00003088-200443150-00005 PMid: 15568891

13. Ethical principles for medical research involving Human Subjects, World Medical Association, Helsinki, Finland, 1964.

Retrieved from: https://www.who.int/bulletin/archives /79(4)373.pdf;

Retrieved on: Jan. 13, 2018

14. M. Unger, "Pharmacokinetic drug interactions involving Ginkgo biloba,” Drug Metabol. vol. 45, no. 3, pp. $353-385$, Aug. 2013.

DOI: $10.3109 / 03602532.2013 .815200$ PMid: 23865865

15. L. T. Vieira, S. M. Huang, "Botanical-drug interactions: a scientific perspective," Planta Med. vol. 78, no. 13, pp. $1400-1415$, Sep. 2012.

DOI: $10.1055 / \mathrm{s}-0032-1315145$ PMid: 22864989

16. M. Cvetkovic, D. Ilic, M. Nikolic, N. Stosic, M. Randjelovic, "Monitoring of the nutritional intake of folic acid among pregnant women in Niš," Facta Universitatis., vol. 13, no. 3, pp. 239-245, 2016. DOI: $10.22190 / F U W L E P 1603239 C$

17. D. Stojanovic, D. Markovic, "Nutrigenomika - nauka za 21.vek," Vojnosanitetski pregled., vol. 68., br. 9, str. 786 - 791, 2011. (D. Stojanovic, D. Markovic, "Nutrigenomics - science for the $21^{\text {st }}$ century," Military Medical Review, vol. 68, no. 9, pp. 786 - 791, 2011.) DOI: $10.2298 /$ VSP1109786S

18. Interactions by Herb or Supplement, University of Maryland Medical Center, Greenspring (MD), USA, 2007.

Retrieved from: http://www.umm.edu/altmed/ConsLo okups/InteractionsByHerbSupp.html;

Retrieved on: Jan. 12, 2007

19. A. Fugh-Berman, "Herb-drug interactions," Lancet. vol. 355, no. 9198, pp. 134 - 138, Feb. 2000. DOI: 10.1016/So140-6736(99)06457-0

20. V. Butterweck et al., "Pharmacokinetic herb-drug interactions: are preventive screenings necessary and appropriate," Planta Med. vol. 70, no. 9, pp. $784-791$, Sep. 2004.

DOI: $10.1055 / \mathrm{s}-2004-827223$

PMid: 15386186
21. L. Rodriguez-Fragoso et al., "Potential risks resulting from fruit/vegetable-drug interactions: effects on drugmetabolizing enzymes and drug transporters," J. Food Sci., vol. 76, no. 4, pp. 112 - 124, May 2011.

DOI:10.1111/j.1750-3841.2011.02155.x PMid: 22417366

22. E. Nutescu, I. Chuatrisorn, E. Hellenbart, Drug and dietary interactions of warfarin and novel oral anticoagulants: an update, J. Thromb. Thrombolysis.vol. 31, no.3, pp. 326-343. Apr 2011. DOI: $10.1007 / \mathrm{s} 11239-011-0561-1$ PMid: 21359645

23. R. Nowack, "Cytochrome P450 enzyme, and transport protein mediated herb-drug interactions in renal transplant patients: grapefruit juice, St John's Wort and beyond!" Nephrology, vol. 13, no. 4, pp. 337 - 347, Jun. 2008.

DOI: $10.1111 / \mathrm{j} .1440-1797.2008 .00940 . \mathrm{x}$ PMid: 18363644

24. J. Boullata, "Natural health product interactions with medication," Nutr. Clin. Pract., vol. 20, no. 1, pp. $33-51$, Feb. 2005.

DOI: $10.1177 / 011542650502000133$

PMid: 16207645

25. P. M. Leite, M. A. P. Martins, R. O. Castilho, "Review on mechanisms and interactions in concomitant use of herbs and warfarin therapy," Biomed. Pharmacother., vol. 83 , pp. $14-21$, Oct. 2016.

DOI: 10.1016/j.biopha.2016.06.012

26. E. M. Williamson, S. Driver, K. Baxter, "Stockley's Herbal Medicines Interactions: A Guide to the Interactions of Herbal Medicines. Second ed.," Pharmaceutical Press, vol. 102, no. 3, pp. $221-222$, Jul. 2014.

DOI: $10.3163 / 1536-5050.102 .3 .018$

PMCid: PMC4076137

27. D. M. Qato et al., "Use of prescription and over the counter medications and dietary supplements among older adults in the United States," JAMA., vol. 300, no. 24, pp. $2867-2878$, Dec. 2008.

DOI: $10.1001 /$ jama.2008.89

PMid: 19109115

Drugs, Herbs and Supplements, NIH MedlinePlus, Bethesda (MD), USA, 2007.

Retrieved from: https://medlineplus.gov/druginformati on.html;

Retrieved on: Jun. 14, 2018

28. J. P. Gonzalez et al., "Influence of vitamin $\mathrm{C}$ on the absorption and first pass metabolism of propranolol," Eur. J. Clin. Pharmacol., vol. 48, no. 3-4. pp. 295 - 297, Jul. 1995.

DOI: $10.1007 /$ BFo0198315

PMid: 7589058 